\title{
Prediction and validation of total and regional fat mass by B-mode ultrasound in Japanese pre-pubertal children
}

\author{
Taishi Midorikawa ${ }^{1,2 *}$, Megumi Ohta ${ }^{2,3}$, Yuki Hikihara ${ }^{4}$, Suguru Torii ${ }^{2}$, Michael G. Bemben ${ }^{5}$ \\ and Shizuo Sakamoto ${ }^{2}$ \\ ${ }^{1}$ College of Health and Welfare, J.F. Oberlin University, 3758 Tokiwamachi, Machida, Tokyo 194-0294, Japan \\ ${ }^{2}$ Faculty of Sport Sciences, Waseda University, 2-579-15 Mikajima, Tokorozawa, Saitama 359-1192, Japan \\ ${ }^{3}$ Faculty of Human Sciences, Kanazawa Seiryo University, 10-1 Ushi, Gosho-machi, Kanazawa, Ishikawa 920-8620, Japan \\ ${ }^{4}$ Faculty of Engineering, Chiba Institute of Technology, 2-1-1 Shibazono, Narashino, Chiba 275-0023, Japan \\ ${ }^{5}$ Department of Health and Exercise Science, University of Oklaboma, Norman, OK, USA
}

(Received 15 February 2010 - Revised 7 November 2010 - Accepted 8 February 2011 - First published online 9 May 2011)

\section{Abstract}

The present study was performed to develop regression-based prediction equations for fat mass by ultrasound in Japanese children and to investigate the validity of these equations. A total of 127 healthy Japanese pre-pubertal children aged 6-12 years were randomly separated into two groups: the model development group (fifty-four boys and forty-four girls) and the validation group (eighteen boys and eleven girls). Total body, trunk, arm and leg fat masses were initially determined by dual-energy X-ray absorptiometry (DXA, Delphi A-QDR whole-body scanner; Hologic, Inc., Bedford, MA, USA). Then, fat thickness was measured by B-mode ultrasound ( $5 \mathrm{MHz}$ scanning head) at nine sites (arm: lateral forearm, anterior and posterior upper arm; trunk: abdomen and subscapular; leg: anterior and posterior thigh, anterior and posterior lower leg). Regression analyses were used to describe the relationships between the site-matched fat masses (total body, arm, trunk and leg) obtained by DXA and ultrasound in the development group. When these fat mass prediction equations were applied to the validation group, the measured total and regional fat mass was very similar to the predicted fat mass (mean difference calculated as predicted - measured fat mass $\pm 2 \mathrm{sD}$; total body $0 \cdot 1(\mathrm{SD} 0 \cdot 5) \mathrm{kg}$, arm $0 \cdot 1$ (SD $0 \cdot 3$ ) $\mathrm{kg}$, trunk $-0 \cdot 1$ (SD $0.3) \mathrm{kg}$, leg 0.1 (SD 0.5) kg for boys; total body 0.5 (SD 1.3$) \mathrm{kg}$, arm 0.0 (SD 0.3) kg, trunk 0.1 (sD 0.8) kg, leg 0.3 (SD 0.6) kg for girls), and the Bland-Altman analysis did not indicate a bias. These results suggest that ultrasound-derived prediction equations for boys and girls are useful for estimating total and regional fat mass.

Key words: Dual-energy X-ray absorptiometry: Fat mass: Children: Ultrasound: Prediction equations

The prevalence of obesity in children has increased worldwide; however, the pattern of fat distribution rather than total fat mass may be more closely related to the risk of developing the metabolic syndrome and other related diseases. In fact, it has been reported that abdominal fat distribution is associated with cardiovascular risk factors independent of

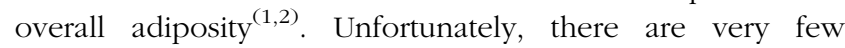
simple, effective and affordable field methods to accurately and non-invasively estimate total and regional fat mass in children.

The method of dual-energy X-ray absorptiometry (DXA) can provide precise, reliable and safe measurements of regional and whole-body fat mass in children, and is debatably considered the 'gold standard' for measuring fat and fat-free body mass. However, DXA methods for estimating fat mass require expensive equipment and specialised facilities. Because of these limitations and the need to be able to measure large groups of subjects, a field technique is warranted for being able to assess total and regional fat mass in children.

Our previous research has allowed the development of ultrasound-derived prediction equations for estimating total and regional (i.e. arm, trunk, thigh and lower leg) fat mass in adult males and females ${ }^{(3)}$. Ultrasound itself is a non-invasive, safe measure of fat thickness of the extremities and trunk, even in children ${ }^{(4)}$. Additionally, a compact-type ultrasound machine is easily portable to use during field research when assessing fat mass for large groups of subjects. However, there are currently no developed prediction equations for estimating total and regional fat mass in children by ultrasound.

Abbreviations: CCC, Lin's concordance correlation coefficient; DXA, dual-energy X-ray absorptiometry.

*Corresponding author: T. Midorikawa, fax +81 42797 8426, email taishi@obirin.ac.jp 
Table 1. Subject characteristics and ultrasound measurements of fat thickness $(\mathrm{cm})$ (Mean values and standard deviations)

\begin{tabular}{|c|c|c|c|c|c|c|c|c|}
\hline \multirow[b]{3}{*}{ Prediction model } & \multicolumn{4}{|c|}{ Development } & \multicolumn{4}{|c|}{ Validation } \\
\hline & \multicolumn{2}{|c|}{ Boys ( $n 54)$} & \multicolumn{2}{|c|}{ Girls ( $n$ 44) } & \multicolumn{2}{|c|}{ Boys $(n 18)$} & \multicolumn{2}{|c|}{ Girls $(n 11)$} \\
\hline & Mean & SD & Mean & SD & Mean & SD & Mean & SD \\
\hline Age (years) & 10 & 2 & 9 & 2 & 9 & 2 & 9 & 2 \\
\hline Standing height $(\mathrm{m})$ & 1.38 & 0.11 & 1.37 & 0.13 & 1.37 & 0.13 & 1.35 & 0.12 \\
\hline$Z$ score* $^{\star}$ & 0.19 & 0.92 & 0.22 & 1.09 & 0.22 & 0.87 & 0.45 & $1 \cdot 14$ \\
\hline Body mass (kg) & $32 \cdot 8$ & $9 \cdot 0$ & 31.9 & $9 \cdot 6$ & $31 \cdot 7$ & $10 \cdot 3$ & $30 \cdot 8$ & $8 \cdot 6$ \\
\hline$Z$ score $^{\star}$ & 0.11 & 1.03 & -0.01 & 1.05 & -0.10 & 0.94 & 0.15 & 1.23 \\
\hline $\mathrm{BMI}\left(\mathrm{kg} / \mathrm{m}^{2}\right)$ & $17 \cdot 0$ & 2.5 & $16 \cdot 7$ & 2.5 & $16 \cdot 4$ & $2 \cdot 6$ & $16 \cdot 6$ & $3 \cdot 2$ \\
\hline Fat $(\%)$ & $22 \cdot 3$ & $7 \cdot 4$ & $25 \cdot 4$ & $5 \cdot 4$ & $21 \cdot 2$ & $6 \cdot 0$ & $27 \cdot 8$ & $8 \cdot 4$ \\
\hline \multicolumn{9}{|l|}{ Fat thickness $(\mathrm{cm})$} \\
\hline Lateral forearm & 0.4 & 0.2 & 0.5 & 0.1 & 0.5 & 0.2 & 0.5 & 0.2 \\
\hline Anterior upper arm & 0.4 & 0.2 & 0.4 & 0.2 & 0.4 & 0.2 & 0.5 & 0.2 \\
\hline Posterior upper arm & 0.9 & 0.3 & 1.0 & 0.3 & 0.9 & 0.3 & 1.0 & 0.3 \\
\hline Abdomen & $1 \cdot 1$ & $1 \cdot 1$ & $1 \cdot 1$ & 0.8 & 0.9 & 0.8 & 1.3 & 0.9 \\
\hline Sabscapular & $0 \cdot 6$ & 0.4 & 0.7 & 0.3 & 0.6 & 0.3 & 0.9 & 0.4 \\
\hline Anterior thigh & 0.8 & 0.3 & 0.9 & 0.2 & 0.7 & 0.3 & 0.9 & 0.3 \\
\hline Posterior thigh & $0 \cdot 8$ & 0.4 & 0.9 & 0.3 & $0 \cdot 8$ & 0.3 & 1.0 & 0.3 \\
\hline Anterior lower leg & 0.4 & 0.1 & 0.4 & 0.1 & 0.4 & 0.1 & 0.5 & 0.1 \\
\hline Posterior lower leg & 0.6 & 0.2 & 0.7 & 0.2 & 0.6 & 0.2 & 0.7 & 0.2 \\
\hline
\end{tabular}

* Standing height and weight are calculated as $Z$ score using the physical fitness standards of Japanese people ${ }^{(13)}$.

Therefore, the present study was performed to develop regression-based prediction equations for fat mass by ultrasound in Japanese children and to investigate the validity of these equations.

\section{Methods}

\section{Subjects}

A total of 127 healthy Japanese pre-pubertal children, aged 6-12 years (as determined by completed years since birth), who were not approaching Tanner stage 2 and peak height velocity, were randomly separated into two groups: the model development group (fifty-four boys and forty-four girls, which included four overweight boys, one obese boy and six overweight girls ${ }^{(5)}$ ) and the validation group (eighteen boys and eleven girls, which included two overweight boys and three overweight girls ${ }^{(5)}$ ) (Table 1). The maturational level of the subjects was assessed using the Tanner scale ${ }^{(6)}$ of pubertal stage development questionnaire. All subjects were physically active (i.e. play outside every day) and did not include any athletes. None of the subjects reported any known pathologies or current medication use. All subjects and their guardians received a verbal and written description of the study, and gave their informed consent to participate before testing. The study protocol was approved by the Ethical Committee of Waseda University, and the present study was conducted according to the guidelines laid down in the Declaration of Helsinki.

Body mass, wearing only minimal clothing, was measured on a digital balance to the nearest $0 \cdot 1 \mathrm{~kg}$, and height was measured on a stadiometer to the nearest $0 \cdot 1 \mathrm{~cm}$. BMI $\left(\mathrm{kg} / \mathrm{m}^{2}\right)$ was calculated as body weight/height squared (Table 1).

Table 2. Predictive equations for dual-energy X-ray absorptiometry (DXA)-measured total body and regional fat mass (FM) from fat thickness using B-mode ultrasound

\begin{tabular}{|c|c|c|c|c|}
\hline FM (kg) & Equations & $R^{2}$ & $\mathrm{CCC}$ & SEE \\
\hline \multicolumn{5}{|c|}{ Boys ( $n 54)$} \\
\hline Total $^{\star}$ & $\mathrm{FM}_{\mathrm{DXA}}=0.9440 \times\left(\mathrm{FTH}_{\text {ultrasound }} \times \mathrm{Ht}\right)-1.7280$ & 0.96 & 0.98 & 1.01 \\
\hline Arm† & $\mathrm{FM}_{\mathrm{DXA}}=0.6311 \times\left(\mathrm{FTH}_{\text {ultrasound }} \times \mathrm{Ht}\right)-0.5691$ & 0.89 & 0.94 & 0.24 \\
\hline Trunk & $\mathrm{FM}_{\mathrm{DXA}}=0.9953 \times\left(\mathrm{FTH}_{\text {ultrasound }} \times \mathrm{Ht}\right)+0.3257$ & 0.91 & 0.95 & 0.67 \\
\hline Leg§ & $\mathrm{FM}_{\mathrm{DXA}}=1.2487 \times\left(\mathrm{FTH}_{\text {ultrasound }} \times \mathrm{Ht}\right)-1.2526$ & 0.92 & 0.96 & 0.55 \\
\hline \multicolumn{5}{|c|}{ 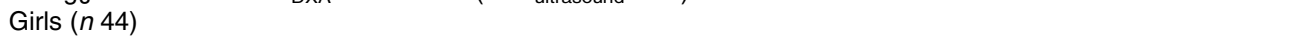 } \\
\hline Total $^{*}$ & $\mathrm{FM}_{\mathrm{DXA}}=0.9260 \times\left(\mathrm{FTH}_{\text {ultrasound }} \times \mathrm{Ht}\right)-1.4100$ & 0.96 & 0.98 & 0.70 \\
\hline Arm† & $\mathrm{FM}_{\mathrm{DXA}}=0.6523 \times\left(\mathrm{FTH}_{\text {ultrasound }} \times \mathrm{Ht}\right)-0.6224$ & 0.84 & 0.92 & 0.22 \\
\hline Trunk $\ddagger$ & $\mathrm{FM}_{\mathrm{DXA}}=0.9622 \times\left(\mathrm{FTH}_{\text {ultrasound }} \times \mathrm{Ht}\right)+0.5257$ & 0.92 & 0.96 & 0.44 \\
\hline Leg§ & $\mathrm{FM}_{\mathrm{DXA}}=1.1747 \times\left(\mathrm{FTH}_{\text {ultrasound }} \times \mathrm{Ht}\right)-0.9620$ & 0.92 & 0.96 & 0.42 \\
\hline
\end{tabular}

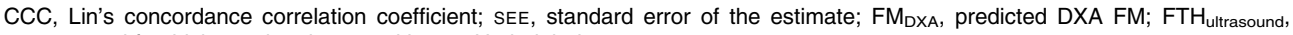
measured fat thickness by ultrasound in $\mathrm{cm}$; Ht, height in $\mathrm{m}$.

* Arm FTH + trunk FTH + leg FTH.

† Lateral forearm FTH + anterior and posterior upper arm FTH.

‡ Abdomen FTH + subscapular FTH.

$\S$ Anterior and posterior thigh FTH + anterior and posterior lower leg. 


\section{Dual-energy X-ray absorptiometry}

Total and regional fat mass was measured using DXA (Delphi A-QDR, version 12.4:3 Pediatric Whole body; Hologic, Inc., Bedford, MA, USA). Fat masses were separated into discrete regions using DXA regional computer-generated default lines on the anterior planogram view with manual adjustments. The 'head and neck' region was defined as the area above the line connecting bilateral acromions. The 'arm' region was defined as the area distal to the line connecting the axilla and the glenohumeral joint space. The 'leg' region was defined as the area distal to the line tangent to ischium and the upper edge of the greater trochanter. The remaining area was defined as the 'Trunk'. The total body fat mass value was the sum of the arm, trunk and leg fat mass values, which did not include the fat mass of head and neck areas. The estimated CV for DXA fat mass measurements from test-retest analyses was determined to be $<1 \%$.

\section{Predicted fat mass by ultrasound}

B-mode ultrasonographic fat thicknesses were scanned using a real-time linear electronic scanner with a $5 \mathrm{MHz}$ scanning head (SSD-1000; Aloka, Tokyo, Japan). The scanning head was prepared with water-soluble transmission gel that provided acoustic contact without depression of the skin surface. The scanner was placed perpendicular to the tissue interface at previously determined marked sites. Fat thicknesses were obtained at nine sites from the anterior and posterior surfaces of the body as described previously ${ }^{(4)}$. The sites included the lateral forearm, anterior and posterior upper arm; abdomen and subscapular; anterior and posterior thigh, anterior and posterior lower leg. The nine anatomical landmarks for the chosen sites were defined as follows: 'lateral forearm' was on the anterior surface, $30 \%$ proximally between the styloid process of the wrist and the head of the radius near the elbow; 'anterior' and 'posterior upper arm' was on the anterior and posterior surfaces of the upper arm, both $60 \%$ distally between the lateral epicondyle of the humerus near the elbow and the acromial process of the scapula at the shoulder; 'abdomen' was at a distance $2-3 \mathrm{~cm}$ to the right of the umbilicus; 'anterior' and 'posterior thigh' was on the anterior and posterior surfaces of the upper leg, midway between the lateral condyle of the femur near the knee and the greater trochanter at the hip; 'anterior' and 'posterior lower leg' was on the anterior and posterior surfaces of the lower leg, 30\% proximally between the lateral malleolus of the fibula near the ankle and the lateral condyle of the tibia near the knee. Fat thickness was measured directly from the screen using calipers and was determined to be the distance from the skin to the fat-muscle interface ${ }^{(7)}$. The reliability of image reconstruction and distance measurements was confirmed by comparing the ultrasonic and manual measurements of tissue thicknesses in human cadavers, with the $\mathrm{CV}$ from test-retest analyses being about $1 \%{ }^{(8)}$.

Based on previous research that developed regression-based prediction equations for estimating muscle mass using ultrasound in adults ${ }^{(9)}$, the parameters of the ultrasound prediction equations for these different fat masses were determined as fat thickness (in cm) $\times$ standing height (in $\mathrm{m}$ ) (i.e. 'Arm' = lateral forearm + anterior and posterior upper arm fat thicknesses; 'trunk' $=$ abdomen + subscapular fat thicknesses; 'leg' = anterior and posterior thigh + anterior and posterior lower leg fat thicknesses; 'total' $=$ 'arm' + 'trunk' + 'leg'). It may be suitable for fat thickness ${ }^{2} \times$ height for the predicting variable. However, the predicted accuracy $\left(R^{2}\right.$ value) using fat thickness ${ }^{2} \times$ height was lower than using the fat thickness $\times$ height except for the arm region. Moreover, in the prediction model, the $R^{2}$ value using the length of the forearm, upper arm, thigh and lower leg was similar to the values that used body height. Since it is easier to measure body height compared
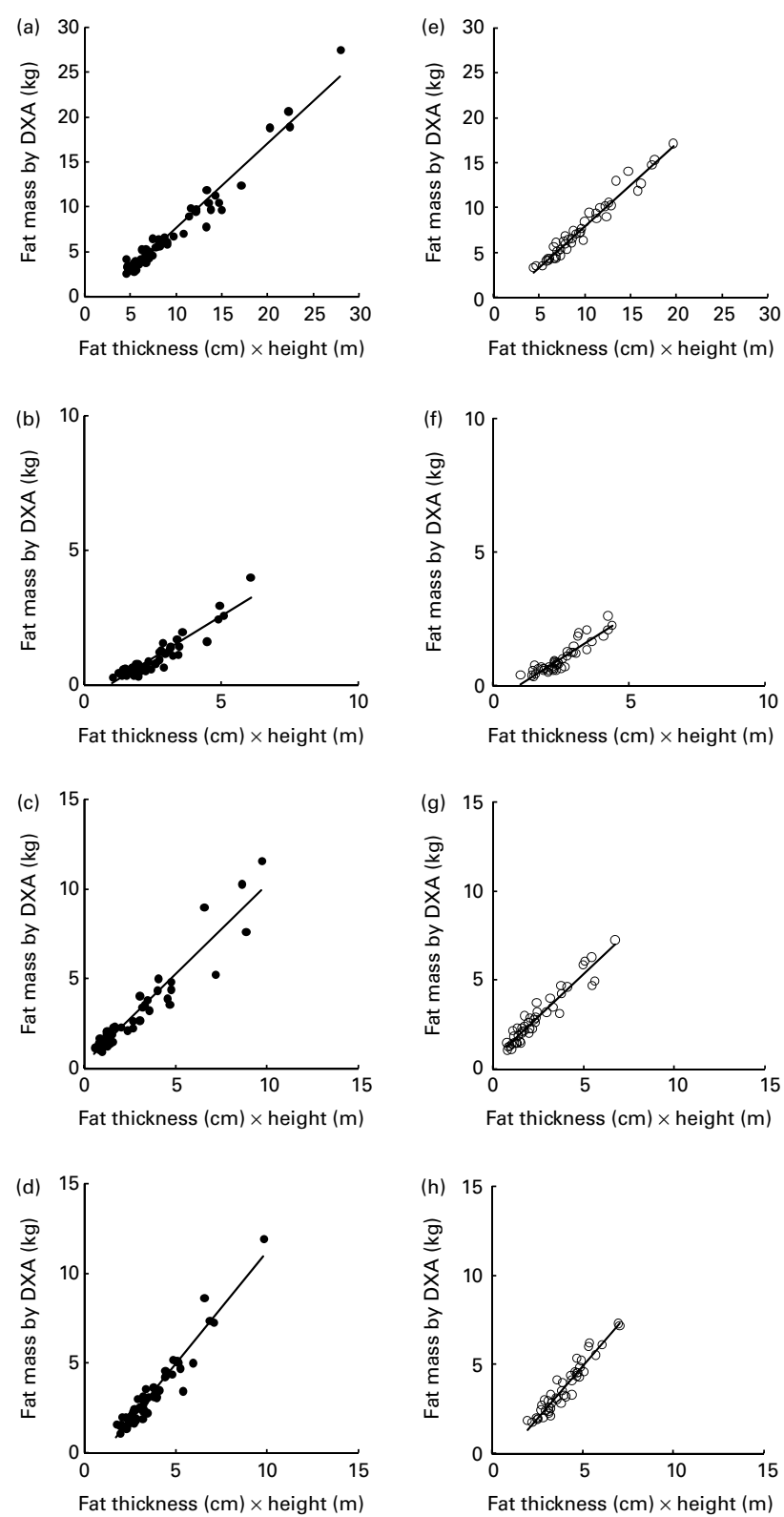

Fig. 1. Relationship between dual-energy X-ray absorptiometry (DXA)measured fat mass and fat thickness $\times$ height measurements by ultrasound. Boys (๑, n 54; (a) total, (b) arm, (c) trunk, (d) leg). Girls (○, n 44; (e) total, (f) arm, (g) trunk, (h) leg). 
with limb lengths, standing height was used to express the length factor of the fat mass. Total body fat mass did not include the head and neck areas.

\section{Statistics}

All results are expressed as means and standard deviations. Regression analyses were used to describe the relationships between the DXA-measured fat masses and the fat thickness $\times$ height measurements at each regional area for boys and girls. The difference between the measured and the predicted fat masses was examined using paired $t$ tests. Agreement of fat masses between the measured and predicted values was further examined by plotting the differences in predicted values against the means with limits of agreement (mean difference \pm 2 sD of the differences: the $95 \%$ limits of agreement, which gives an indication of the precision of the method), as suggested by Bland \& Altman $^{(10)}$. Lin's concordance correlation coefficient (CCC) was used as a further measure of agreement ${ }^{(11)}$. McBride ${ }^{(12)}$ suggests the following descriptive scale for CCC values: CCC $<0.90$ is poor strength of agreement; $0.90-0.95$ is moderate; $0.95-0.99$ is substantial; $>0.99$ is almost perfect. Statistical analyses were performed using SPSS for Windows (version 17.0J; SPSS, Inc., Chicago,

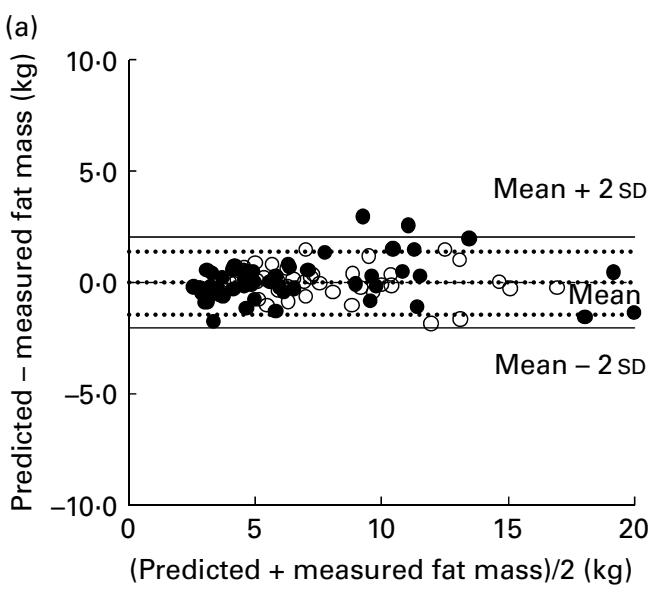

(c)

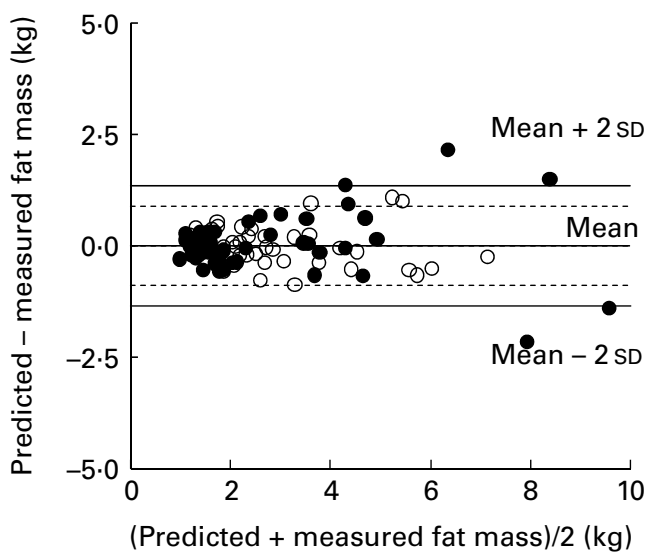

IL, USA) and MedCalc for Windows (version 11.3.6; MedCalc Software, Mariakerke, Belgium). Differences were regarded as significant when the probabilities were $<0 \cdot 05$.

\section{Results}

The physical characteristics and ultrasound fat thickness measurements are summarised in Table 1. As mean height and weight values were comparable with the physical fitness standards of Japanese people ${ }^{(13)}$, this indicated that the mass and distribution of fat for the subjects in the present study should be representative of Japanese pre-pubertal children.

Strong significant correlations were observed between the site-matched fat masses (total body, arms, trunk and legs) measured by DXA and the fat thickness $\times$ height measurements obtained by ultrasound in the model development group of boys and girls $\left(R^{2} 0.84-0.96, P<0.01\right.$; CCC $=0.92-$ 0.98 ; standard error of the estimate $=0 \cdot 22-1 \cdot 01 \mathrm{~kg}$; Table 2 and Fig. 1). The Bland-Altman analysis for the development group did not indicate a bias for either boys or girls (Fig. 2). The mean difference \pm 2 sD between the measured and predicted fat masses for the development group was as follows: for boys ( $n$ 54), arm 0.0 (SD 0.5) kg, trunk 0.0 (SD 1.4) kg, leg $0 \cdot 0(\mathrm{SD} 1 \cdot 1) \mathrm{kg}$ and total body $0 \cdot 0(\mathrm{SD} 2 \cdot 0) \mathrm{kg}$; for girls

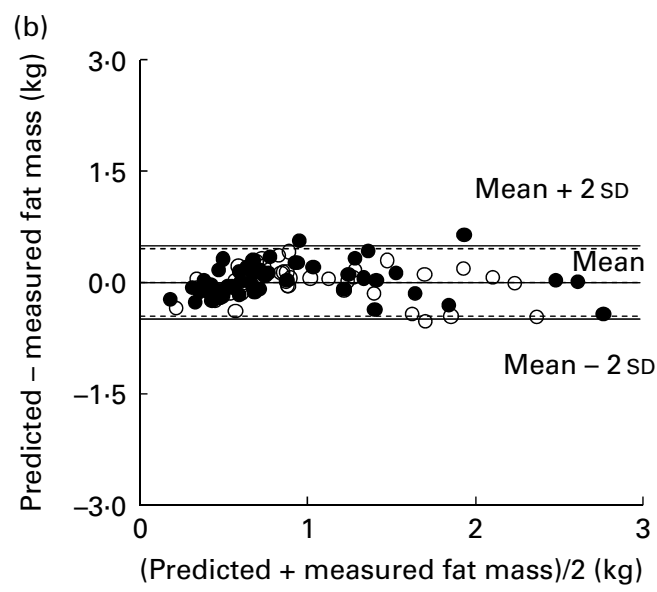

(d)

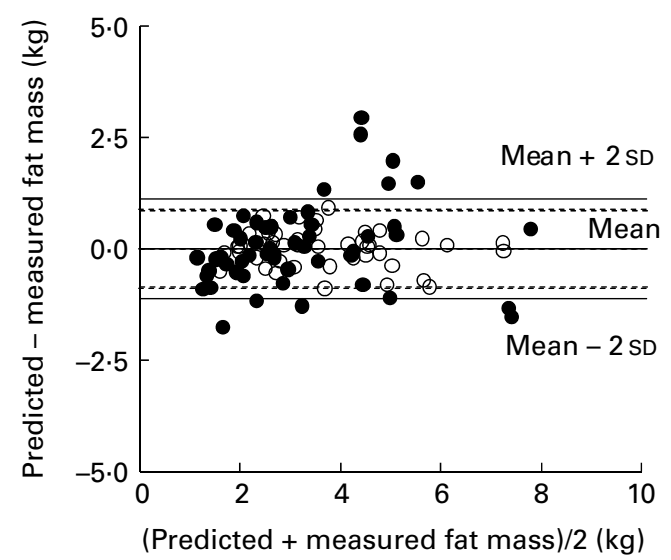

Fig. 2. Bland-Altman analysis for the development group. Values are means and standard deviations ( $\pm 2 \mathrm{sD})$. Solid line for boys (•, $n 54)$ and dotted line for girls (O, n 44). (a) Total, (b) arm, (c) trunk, (d) leg. 
Table 3. Measured and predicted fat mass in total body and regional segments for validation boys and girls (Mean values and standard deviations)

\begin{tabular}{|c|c|c|c|c|c|c|c|c|c|c|c|c|c|c|c|c|}
\hline \multirow[b]{3}{*}{ Fat mass $(\mathrm{kg})$} & \multicolumn{8}{|c|}{ Boys (n 18) } & \multicolumn{8}{|c|}{ Girls (n11) } \\
\hline & \multicolumn{2}{|c|}{ Measured } & \multicolumn{2}{|c|}{ Predicted } & \multicolumn{2}{|c|}{$\begin{array}{c}\text { Mean } \\
\text { difference* }\end{array}$} & \multirow[b]{2}{*}{$P+$} & \multirow[b]{2}{*}{$\mathrm{CCC}$} & \multicolumn{2}{|c|}{ Measured } & \multicolumn{2}{|c|}{ Predicted } & \multicolumn{2}{|c|}{$\begin{array}{c}\text { Mean } \\
\text { difference }^{*}\end{array}$} & \multirow[b]{2}{*}{$P+$} & \multirow[b]{2}{*}{$\mathrm{CCC}$} \\
\hline & Mean & SD & Mean & SD & Mean & SD & & & Mean & SD & Mean & SD & Mean & SD & & \\
\hline Total & $6 \cdot 4$ & $4 \cdot 0$ & $6 \cdot 5$ & $4 \cdot 2$ & 0.1 & 0.5 & 0.80 & 0.99 & $8 \cdot 1$ & $3 \cdot 7$ & $8 \cdot 5$ & $3 \cdot 6$ & 0.5 & $1 \cdot 3$ & 0.66 & 0.93 \\
\hline Arm & 0.8 & 0.6 & 0.9 & 0.6 & 0.1 & 0.3 & 0.13 & 0.91 & $1 \cdot 1$ & 0.5 & $1 \cdot 1$ & 0.5 & 0.0 & 0.3 & 0.92 & 0.84 \\
\hline Trunk & 2.5 & $1 \cdot 8$ & 2.4 & 1.7 & -0.1 & 0.3 & 0.37 & 0.98 & $3 \cdot 2$ & $1 \cdot 7$ & 3.4 & $1 \cdot 6$ & 0.1 & 0.8 & 0.61 & 0.87 \\
\hline Leg & $3 \cdot 0$ & 1.6 & $3 \cdot 1$ & 1.8 & 0.1 & 0.5 & 0.41 & 0.96 & 3.7 & 1.6 & $4 \cdot 0$ & 1.5 & 0.3 & 0.6 & 0.12 & 0.92 \\
\hline
\end{tabular}

CCC, Lin's concordance correlation coefficient.

${ }^{*}$ Calculated as (predicted - measured fat mass).

$+P$ value for paired $t$ tests: measured $v$. predicted fat mass.

( $n$ 44), arm $0.0(\mathrm{SD} 0.5) \mathrm{kg}$, trunk $0.0(\mathrm{SD} 0.9) \mathrm{kg}$, leg 0.0 (SD $0 \cdot 9) \mathrm{kg}$ and total body $0 \cdot 0$ (SD 1.4) kg (Fig. 2).

When these fat mass prediction equations were applied to the validation groups, the measured total and regional fat masses were also very similar to the predicted fat masses in boys and girls, respectively (Table 3). CCC showed relatively high agreement between the measured and predicted fat masses except for the arm and trunk areas for girls

(a)

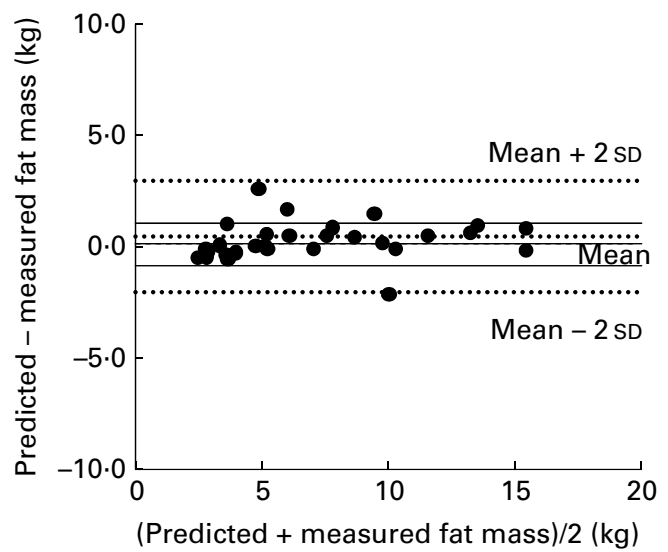

(c)

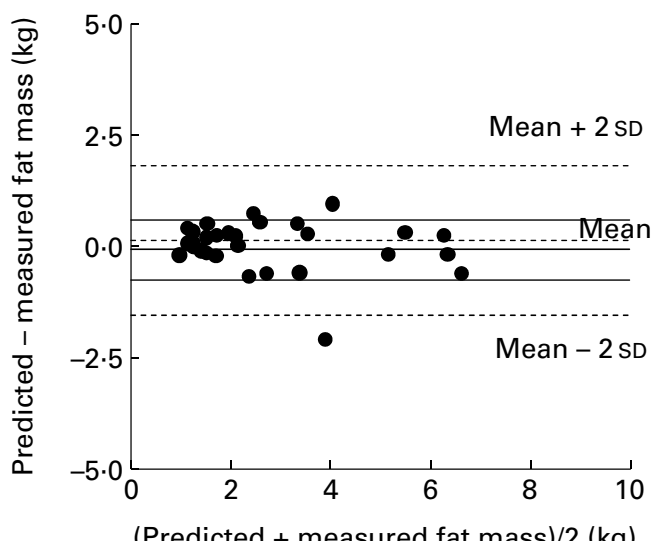

(Table 3). The Bland-Altman analysis for the validation group did not indicate a bias for either boys or girls (Fig. 3).

\section{Discussion}

Prediction equations for estimating fat mass using B-mode ultrasound first appeared in the literature in the late 1980s when Kuczmarski and colleagues ${ }^{(14,15)}$ developed a regression

(b)

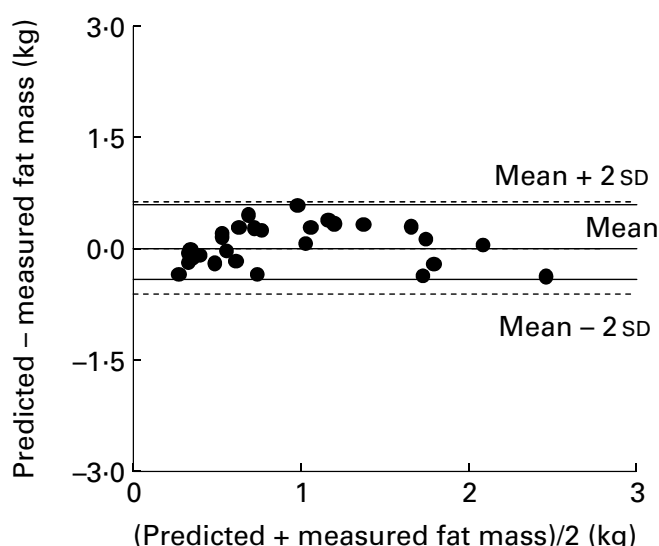

(d)

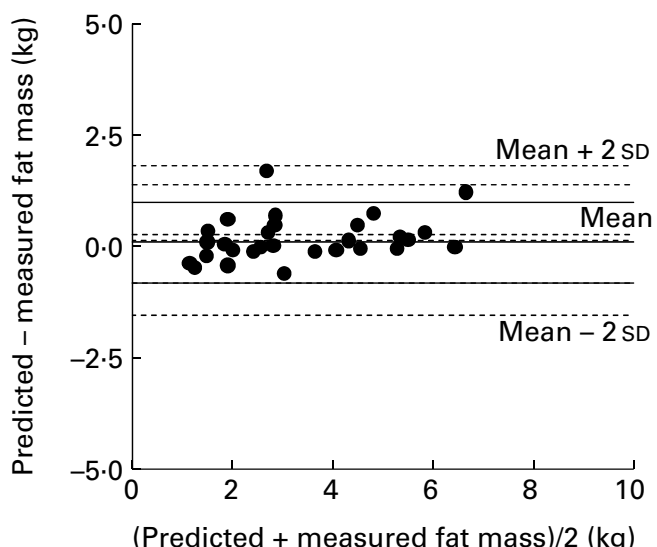

Fig. 3. Bland-Altman analysis for the validation group. Values are means and standard deviations $( \pm 2 \mathrm{SD})$. Solid line for boys $(\bullet, n 18)$ and dotted line for girls $(\bullet, n$ 11). (a) Total, (b) arm, (c) trunk, (d) leg. 
equation for body density using ultrasound in both non-obese and obese adults. In Japan, prediction equations for body density from ultrasound-measured fat thicknesses were also obtained by multiple regression analyses in adult males and females $^{(4)}$, as well as in Japanese Sumo wrestlers ${ }^{(16)}$. However, there have been no prediction equations published for estimating body density or fat mass in children.

Many of the early studies that predicted body density have used underwater weighing as the criterion measure; however, there are many difficulties using this technique with children. On the other hand, DXA provides a much simpler and more reliable technique for obtaining fat mass of children in the present study since underwater weighing is affected by human body water and is an accurate measurement of residual lung volume. Therefore, ultrasound-derived prediction equations for boys and girls, using DXA as the criterion measure, may be extremely useful for estimating fat masses in children.

Our prediction equations for total body fat mass had a moderate standard error of the estimate of $1.01 \mathrm{~kg}(3.1 \%$ fat of mean body mass) for boys and $0.70 \mathrm{~kg}(2 \cdot 2 \%$ fat of mean body mass) for girls, and limits of agreement of $\pm 2.0 \mathrm{~kg}$ for boys and $\pm 1.4 \mathrm{~kg}$ for girls. When compared with the field methods of a previous study to predict fat mass using skinfold calipers for children, the standard error of the estimate for the present study was relatively low (e.g. about $4 \%$ fat according to the Slaughter et $a l .{ }^{(17)}$ equation, about 3-5\% fat according to Deurenberg et al. $\left.{ }^{(18)}\right)$. Moreover, given the developed equations for fat mass from triceps and subscapular skinfold thicknesses using skinfold calipers for the same subjects in the present study ( $\mathrm{T}$ Midorikawa, unpublished results), the standard error of the estimate $(1.54 \mathrm{~kg}, 4.7 \%$ fat for boys and $0.99 \mathrm{~kg}, 3.2 \%$ fat for girls) and limits of agreement $( \pm 3.1 \mathrm{~kg}$ for boys and $\pm 2 \cdot 0 \mathrm{~kg}$ for girls) were relatively high when compared with the ultrasound-derived prediction equations. In addition, CCC of the present prediction equation for total fat mass was 0.98, which indicates a substantial strength of agreement. Based on the estimation accuracy and the ease of obtaining the measurements, the ultrasound-derived prediction of total fat mass holds a great deal of potential as a technique for assessing fat mass in children, especially in a field setting.

There are a number of limitations in the present study that need to be addressed. First, since the equations were created and validated using fat measurements from a Hologic Delphi A-QDR, these equations cannot be applied to other models or manufacturers of DXA machines because the fat masses assessed by different DXA machines will vary ${ }^{(19)}$. Second, it is not possible to establish the cardiovascular risk factors associated with the present levels of fatness in the present study. Third, these equations were developed using Japanese children and may not apply to other children.

In summary, we have developed prediction equations that are useful for determining group means, for total and regional fat masses in children using B-mode ultrasound. Future research will focus on developing prediction equations for skeletal muscle mass in children using ultrasound.

\section{Acknowledgements}

Heartfelt thanks are due to the subjects who participated in the present study and their guardians. The present study was supported in part by the Ministry of Education, Science, Sports and Culture of Japan (grant no. 18800054) and the 25th Research Grant in Medical and Health Science of Meiji Yasuda Life Foundation of Health and Welfare. There is no conflict of interest on the part of any of the authors. The contribution of each author to the manuscript was as follows: T. M. drafted the manuscript and did the data analysis; M. O., Y. H. and M. G. B. contributed to the drafting of the manuscript; S. T. and S. S. designed the study.

\section{References}

1. Daniels SR, Morrison JA, Sprecher DL, et al. (1999) Association of body fat distribution and cardiovascular risk factors in children and adolescents. Circulation 99, 541-545.

2. Botton J, Heude B, Kettaneh A, et al. (2007) Cardiovascular risk factor levels and their relationships with overweight and fat distribution in children: the Fleurbaix Laventie Ville Santé II study. Metabolism 56, 614-622.

3. Abe T, Tanaka F, Kawakami Y, et al. (1996) Total and segmental subcutaneous adipose tissue volume measured by ultrasound. Med Sci Sports Exerc 28, 908-912.

4. Abe T, Kondo M, Kawakami Y, et al. (1994) Prediction equations for body composition of Japanese adults by B-mode ultrasound. Am J Hum Biol 6, 161-170.

5. Cole TJ, Bellizzi MC, Flegal KM, et al. (2000) Establishing a standard definition for child overweight and obesity worldwide: international survey. BMJ 320, 1240-1243.

6. Tanner JM (1960) Growth at Adolescence. Oxford: Blackwell Scientific Publications.

7. Midorikawa T, Sanada K, Yoshitomi A, et al. (2009) Is the use of ultrasound-derived prediction equations for adults useful for estimating total and regional skeletal muscle mass in Japanese children? Br J Nutr 101, 72-78.

8. Fukunaga T, Mastuo A, Ishida Y, et al. (1989) Study for measurement of muscle and subcutaneous fat thickness by ultrasonic B-mode method. Jpn J Med Ultrasonics 16, $170-177$.

9. Sanada K, Kearns CF, Midorikawa T, et al. (2006) Prediction and validation of total and regional skeletal muscle mass by ultrasound in Japanese adults. Eur J Appl Physiol 96, 24-31.

10. Bland JM \& Altman DG (1986) Statistical methods for assessing agreement between two methods of clinical measurement. Lancet i, 307-310.

11. Kriemler S, Puder J, Zahner L, et al. (2010) Estimation of percentage body fat in 6- to 13-year-old children by skinfold thickness, body mass index and waist circumference. $\mathrm{BrJ}$ Nutr 104, 1565-1572.

12. McBride GB (2005) A proposal for strength-of-agreement criteria for Lin's concordance correlation coefficient. NIWA Client Report: HAM 2005-062.

13. Tokyo Metropolitan University (1989) Physical Fitness Standards of Japanese People, 4th ed., pp. 22-23, 56-57. Tokyo: Fumaido.

14. Fanelli MT \& Kuczmarski RJ (1984) Ultrasound as an approach to assessing body composition. Am J Clin Nutr 39, 703-709.

15. Kuczmarski RJ, Fanelli MT \& Koch GG (1987) Ultrasonic assessment of body composition in obese adults: overcoming the limitations of the skinfold caliper. Am J Clin Nutr 45, 717-724. 
16. Saito K, Nakaji S, Umeda T, et al. (2007) Development of predictive equations for body density of sumo wrestlers using B-mode ultrasound for the determination of subcutaneous fat thickness. Br J Sports Med 37, $144-148$.

17. Slaughter MH, Lohman TG, Boileau RA, et al. (1988) Skinfold equations for estimation of body fatness in children and youth. Hum Biol 60, 709-723.
18. Deurenberg P, Pieters JJ \& Hautvast JG (1990) The assessment of the body fat percentage by skinfold thickness measurements in childhood and young adolescence. $\mathrm{Br} J$ Nutr 63, 293-303.

19. Tothill P, Avenell A, Love J, et al. (1994) Comparisons between Hologic, Lunar and Norland dual energy X-ray absorptiometers and other techniques used for whole-body soft tissue measurements. Eur J Clin Nutr 48, 781-794. 